\title{
REACTIVITY, STEREO- AND REGIOSELECTIVITY OF DIELS-ALDER REACTIONS BETWEEN FIVE-MEMBERED HETEROCYCLES AND DANISHEFSKY'S DIENE
}

\author{
Romina Brasca ${ }^{\mathrm{a}}$, Maria N. Kneeteman ${ }^{\mathrm{b}}$, Pedro M. E. Mancini ${ }^{\mathrm{b}}$, Walter M. F. Fabian ${ }^{\mathrm{c}}$ \\ ${ }^{a}$ Laboratorio de Desarrollo Analítico y Quimiometría, Facultad de Bioquímica y Ciencias \\ Biológicas, Universidad Nacional del Litoral-CONICET, S3000ZAA Santa Fe, Argentina, \\ rmnbrasca@gmail.com \\ ${ }^{b}$ Laboratorio G. A. Fester, Facultad de Ingeniería Química, Universidad Nacional del Litoral- \\ CONICET, S3000AOM Santa Fe, Argentina, pmancini@fiq.unl.edu.ar, \\ mkneeteman@fiq.unl.edu.ar \\ ${ }^{c}$ Institute of Chemistry, Karl-Franzens-University Graz, A-8010 Graz, Austria, \\ walter.fabian@uni-graz.at
}

\begin{abstract}
Conceptual density functional theory (chemical hardness $\eta$, electronic chemical potential $\mu$, global and local electrophilicity index $\omega$ and $\omega_{k}$, Fukui function $f^{+}{ }_{k}$ ) is used to predict reactivity, stereo- and regioselectivity of the Diels-Alder (DA) reaction between 2-nitropyrrole and its 1tosylated derivative with Danishefsky's diene to yield 5-hydroxyindoles. A detailed mechanistic study of various possible reaction channels is done by DFT [B3LYP/6-31G(d)] calculations. Solvent effects (benzene) are taken into account by the CPCM bulk solvation model. In principle, the nitropyrrole can either act as diene involving the nitro group (hetero Diels-Alder reaction, HAD) or alternatively as alkene in a "normal" Diels-Alder reaction. The experimentally observed product 5-hydroxy-1-tosylindole can be formed either directly by Diels-Alder reaction of the nitropyrrole acting as alkene or by rearrangement of the dihydrooxazine $\mathrm{N}$-oxides. The primary cycloadduct with the nitropyrrole acting as alkene is found to be unstable reacting further by extrusion of nitrous acid to 5-hydroxyindole. Finally, the results are compared with those obtained for the analogous furans, thiophenes, and selenophenes.
\end{abstract}

Keywords: Diels-Alder cycloaddition, Reactivity indices, conceptual DFT, transition states, 


\section{Introduction}

Due to their electron-rich character five-membered heterocycles like furans or pyrroles usually take part in Diels-Alder type reactions as dienes. Substitution by electron-withdrawing groups sufficiently increases the electrophilic character to make possible their reaction as dienophiles with electron-rich dienes, e.g. Danishefsky's diene. ${ }^{1}$ For instance, 3 -acylfurans and 1-tosylated 3acylpyrroles have been shown to undergo cycloaddition reactions even with isoprene in high yields. $^{2}$ In continuation of our previous computational studies concerning Diels-Alder reactions of nitro-substituted furans and thiophenes here we want to present the results of the analogous reaction of 2-nitro-1-tosylpyrrole 2c with Danischefsky's diene 5. ${ }^{3-5}$ Experimentally, the sole product found in this reaction is 5-hydroxy-1-tosylindole (Scheme 1).

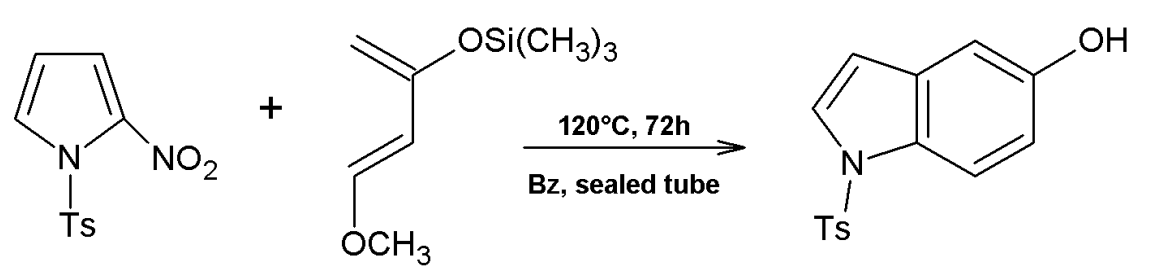

\section{Scheme 1}

First, we will present DFT based reactivity indices to obtain information about the most likely site of attack by the diene. This will be used as a guideline for more detailed mechanistic investigations by quantum chemical calculations. In addition, comparison of these reactivity indices, especially the global electrophilicity $\omega$ as a indicator of the overall reactivity of the 
molecule under consideration, with related five-membered heterocycles (Scheme 2) will be made to put the results into scale.

\begin{tabular}{rrrrrrr} 
& \multicolumn{2}{c}{$\mathbf{x}$} & $\mathbf{R}^{1}$ & & $\mathbf{X}$ & $\mathbf{R}^{\mathbf{1}}$ \\
\cline { 2 - 7 } & $\mathbf{1 a}$ & $\mathrm{O}$ & $\mathrm{H}$ & $\mathbf{3 a}$ & $\mathrm{S}$ & $\mathrm{H}$ \\
& $\mathbf{1 b}$ & $\mathrm{O}$ & $\mathrm{NO}_{2}$ & $\mathbf{3 b}$ & $\mathrm{S}$ & $\mathrm{NO}_{2}$ \\
& $\mathbf{2 a}$ & $\mathrm{NH}$ & $\mathrm{H}$ & $\mathbf{4 a}$ & $\mathrm{Se}$ & $\mathrm{H}$ \\
& $\mathbf{2 b}$ & $\mathrm{NH}$ & $\mathrm{NO}_{2}$ & $\mathbf{4 b}$ & $\mathrm{Se}$ & $\mathrm{NO}_{2}$ \\
& $\mathbf{2 c}$ & $\mathrm{NTOS}$ & $\mathrm{NO}_{2}$ & & &
\end{tabular}

Scheme 2 Structures of the investigated compounds

\section{Computational procedures}

Geometries of all stationary states (reactants, transition structures, intermediates, products) were completely optimized using the B3LYP hybrid density functional ${ }^{6,7}$ with the $6-31 G(d)$ basis set (for selenium the Binning-Curtiss $\mathrm{VTZP}^{8}$ basis set was used) and verified as true minima or transition structures by frequency calculations. Transition structures were further characterized by intrinsic reaction coordinate calculations along both modes corresponding to the imaginary frequency. Thermal corrections to Gibbs free energies were computed by the standard rigid-rotor harmonic oscillator approximation at $T=298,393$, and $438 \mathrm{~K}$. To all structures the geometrical counterpoise and dispersion corrections (gCP-D3) of Grimme et al. ${ }^{9-12}$ were added. Solvent effects (benzene) were treated by the CPCM solvation model $^{13}$ using the $6-31 \mathrm{G}(\mathrm{d}, \mathrm{p})$ basis set. For reactions in solution the appropriate standard state conversion (atm to $\mathrm{M} \mathrm{L}^{-1}$ ) of $R T \ln V_{\mathrm{T}} / V_{0}$ 
was applied to Gibbs free energies. Conceptual density functional theory ${ }^{14-19}$ was used to derive descriptors for reactivity and selectivity (global and local electrophilicity $\omega$ and $\omega_{\mathrm{k}}$ ). Programs used were: Gaussian $09,{ }^{20}$ gCP-D3 for the BSSE and dispersion correction, ${ }^{9-12}$ Open Babel ${ }^{21}$ for file format conversions, and Jmol for visualization. ${ }^{22}$

\section{Results and Discussion}

DFT based reactivity indices. The global electrophilicity $\omega$, defined as

$\omega=\mu^{2} / 2 \eta$

where the chemical hardness $\eta$ and the electronic chemical potential $\mu$ are evaluated from the frontier orbital energies ( $\varepsilon_{\mathrm{HOMO}}$ and $\left.\varepsilon_{\mathrm{LUMO}}\right)$ as

$\eta=\varepsilon_{\text {LUMO }}-\varepsilon_{\text {HOMO }}$

$\mu=\left(\varepsilon_{\mathrm{HOMO}}+\varepsilon_{\mathrm{LUMO}}\right) / 2$

is a useful descriptor of the reactivity of a dienophile towards electron-rich dienes (e.g. Danishefsky's diene 5, Scheme 1). Local electrophilicities $\omega_{\mathrm{k}}$, derived from the global electrophilicity and the respective condensed Fukui function $f_{k}^{+}$of center k,

$\omega_{k}=\omega f_{k}^{+}$

indicate the preferred site of attack of the dienophile by the most nucleophilic atom of the diene (C4 of Danishefsky's diene). 
Table 1 Global electrophilicity indices $\omega$ for compounds 1 - 4 (eV).

\begin{tabular}{|c|c|c|c|c|c|c|}
\hline & \multicolumn{3}{|c|}{ Gas phase } & \multicolumn{3}{|c|}{ Benzene } \\
\hline & $\mu$ & $\eta$ & $\omega$ & $\mu$ & $\eta$ & $\omega$ \\
\hline $1 \mathbf{a}$ & -2.79 & 6.64 & $0.58(0.59)^{\mathrm{a}}$ & -2.84 & 6.64 & 0.61 \\
\hline $1 b$ & -4.93 & 4.83 & 2.51 & -4.90 & 4.69 & 2.57 \\
\hline $2 a$ & -2.05 & 6.87 & $0.31(0.31)^{\mathrm{a}}$ & -2.14 & 6.90 & 0.33 \\
\hline $2 b$ & -4.50 & 4.60 & 2.20 & -4.50 & 4.49 & 2.26 \\
\hline $2 c$ & -4.61 & 4.59 & 2.32 & -4.69 & 4.51 & 2.44 \\
\hline $\mathbf{3 a}$ & -3.27 & 6.13 & 0.87 & -3.32 & 6.13 & 0.90 \\
\hline $3 b$ & -5.02 & 4.73 & 2.66 & -4.99 & 4.62 & 2.70 \\
\hline $\mathbf{4 a}$ & -3.33 & 5.95 & 0.93 & -3.38 & 5.95 & 0.96 \\
\hline $4 b$ & -4.97 & 4.61 & 2.68 & -4.93 & 4.49 & 2.71 \\
\hline
\end{tabular}

Compared with the reference electrophile nitroethene with $\omega=2.61,{ }^{23}$ unsubstituted fivemembered heterocycles $\mathbf{1 a}-\mathbf{4 a}$ are only moderately (3a, 4a) or even marginally (1a, 2a) electrophilic; introduction of a nitro substituent, especially at position 2, substantially increases the global electrophilicity and, hence, reactivity towards electron-rich dienes. According to the 
classification scheme of Domingo et al., ${ }^{23}$ the nitro-substituted derivatives $\mathbf{1 b}-\mathbf{4 b}$ and $\mathbf{2 c}$ can be considered as strong electrophiles. Concerning the effect of the heteroatom, the reactivity increases in the series $\mathrm{O}<\mathrm{S}<\mathrm{Se}$; pyrrole derivatives are less reactive than furans. 1-Tosylation slightly increases the electrophilicity. The effect of taking into account solvation by a bulk solvent model (CPCM) has only little effect on $\omega$.

Table 2 Local electrophilicity indices $\omega_{\mathrm{k}}$ for compounds $\mathbf{1 b}$ and $\mathbf{2 c}(\mathrm{eV})$.

\begin{tabular}{lllll}
\hline & $\mathbf{1 a}$ & & $\mathbf{2 c}$ \\
& Gas phase & Benzene & Gas phase & Benzene \\
C2 & 0.01 & 0.07 & 0.06 & 0.05 \\
C3 & 0.38 & 0.39 & 0.32 & 0.36 \\
C4 & 0.01 & 0.01 & 0.01 & 0.01 \\
C5 & 0.28 & 0.28 & 0.25 & 0.29 \\
\hline
\end{tabular}

According to the local electrophilicity $\omega_{\mathrm{k}}$ the preferred site of attack by electron-rich dienes in polar Diels-Alder reactions is C3 of 2-nitro-substituted five-membered heterocycles. Detailed calculations for all possible cycloaddition modes (site- and regioisomers) are completely in line with this prediction. ${ }^{5}$ Therefore, in the reaction of 2-nitro-1-tosyl-pyrrole with Danishefsky's diene we will concentrate on the following four channels (Scheme 3). 
Mechanistic details of the Cycloaddition Reaction. The individual reactions considered here are depicted in Scheme 3. Calculated relative Gibbs free energies with respect to the separated reactants, 2-nitro-1-tosylpyrrole 2c and Danischefsky's diene $\mathbf{5}$ are collected in Table 3.
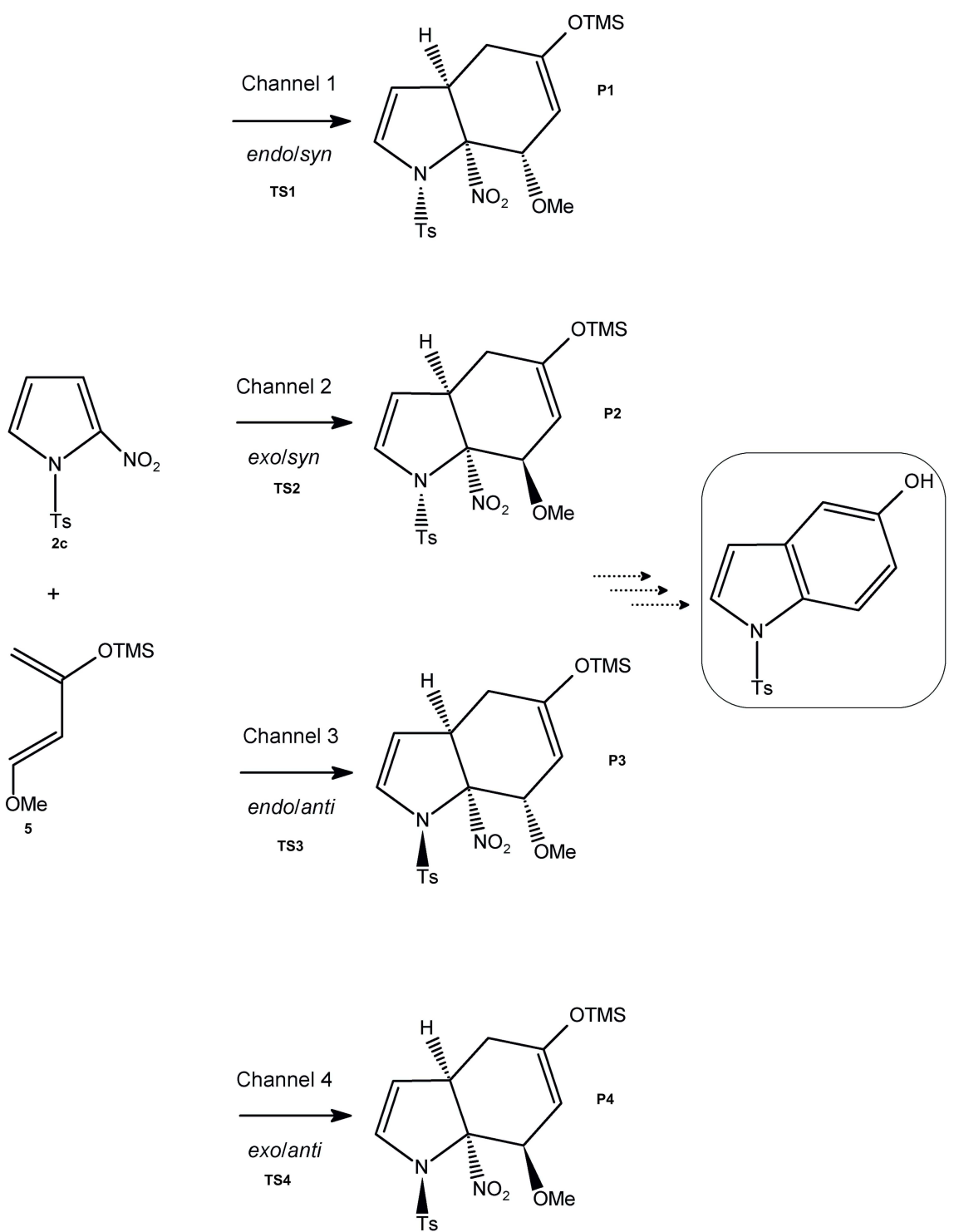

Scheme 3 Investigated reaction paths of the reaction 2-nitro-1-tosylpyrrole 2c with Danishefsky's diene 5. 
Table 3 Relative Gibbs free energies ${ }^{\mathrm{a}} \Delta G_{T}$ for transition structures, intermediates and products of the four reaction channels depicted in Scheme 3 in gas phase and benzene solution at $T=298$, 393, and $438 \mathrm{~K}$.

\begin{tabular}{|c|c|c|c|c|c|c|}
\hline & \multicolumn{3}{|c|}{ gas phase } & \multicolumn{3}{|c|}{ benzene } \\
\hline & $\Delta G_{298}$ & $\Delta G_{393}$ & $\Delta G_{438}$ & $\Delta G_{298}$ & $\Delta G_{393}$ & $\Delta \boldsymbol{G}_{\mathbf{4 3 8}}$ \\
\hline TS1a & 26.9 & 31.8 & 34.2 & 25.7 & 29.8 & 31.8 \\
\hline Int1 & 15.7 & 20.8 & 23.1 & 15.2 & 19.4 & 21.4 \\
\hline TS1b & 25.9 & 31.5 & 34.1 & 24.4 & 29.2 & 31.4 \\
\hline P1 & 0.9 & 6.9 & 9.8 & 0.7 & 5.8 & 8.3 \\
\hline TS2 & 28.0 & 33.0 & 35.4 & 25.4 & 29.7 & 31.7 \\
\hline P2 & 1.7 & 6.7 & 9.1 & 1.0 & 5.2 & 7.2 \\
\hline TS3a & 34.8 & 39.8 & 42.2 & 31.9 & 36.2 & 38.2 \\
\hline Int3 & 18.0 & 22.9 & 25.2 & 16.1 & 20.1 & 22.0 \\
\hline TS4 & 33.8 & 38.8 & 41.2 & 29.0 & 33.3 & 35.2 \\
\hline P4 & -0.9 & 4.5 & 7.1 & -1.7 & 2.9 & 5.0 \\
\hline TS5 & 17.8 & 23.2 & 25.8 & 16.0 & 20.6 & 22.7 \\
\hline P5 & -22.8 & -21.7 & -21.1 & -24.1 & -23.0 & -22.4 \\
\hline
\end{tabular}

${ }^{\mathrm{a}} \mathrm{kcal} \mathrm{mol}{ }^{-1}$ : given relative to the separated reactants $\mathbf{2 c}+\mathbf{5}$. Gibbs free energies for benzene solution (CPCM-B3LYP/6-31G(d,p)//B3LYP/6-31G(d) single point calculations) contain the standard state conversion atm to $\mathrm{M} \mathrm{L}^{1}$. Corrections for dispersion interactions and the BSSE are taken into account by the gCP-D3 method ${ }^{9-12}$. 
Calculated [B3LYP/6-31G(d)] structures of transition states (TS1A, TS1B), intermediate Int1, and product $\mathbf{P 1}$ for channel 1 are depicted in Fig. 1.

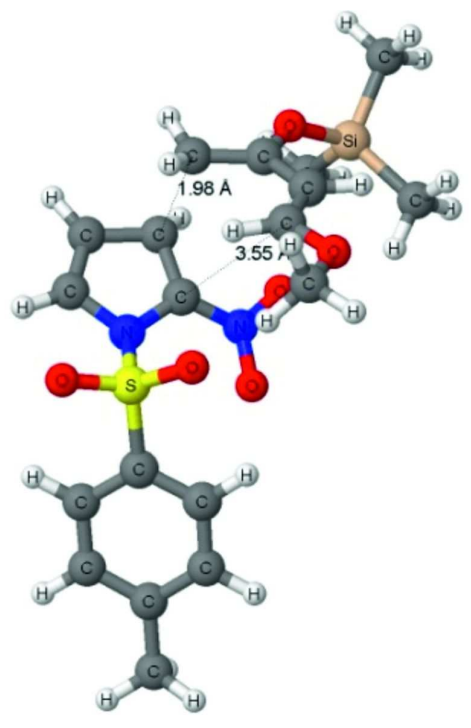

TS1A

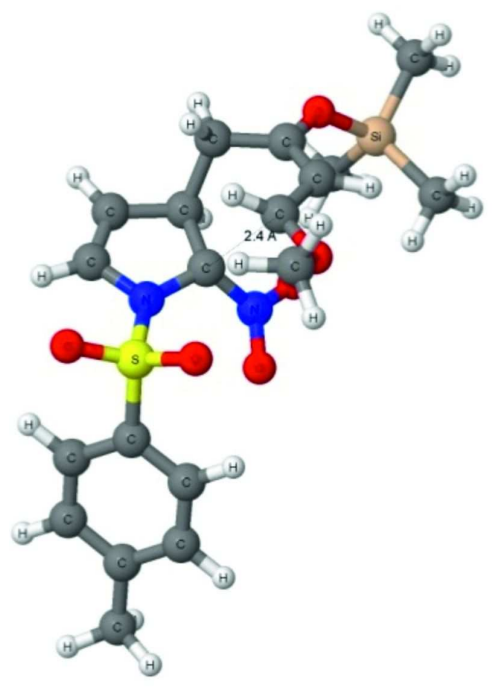

TS1B

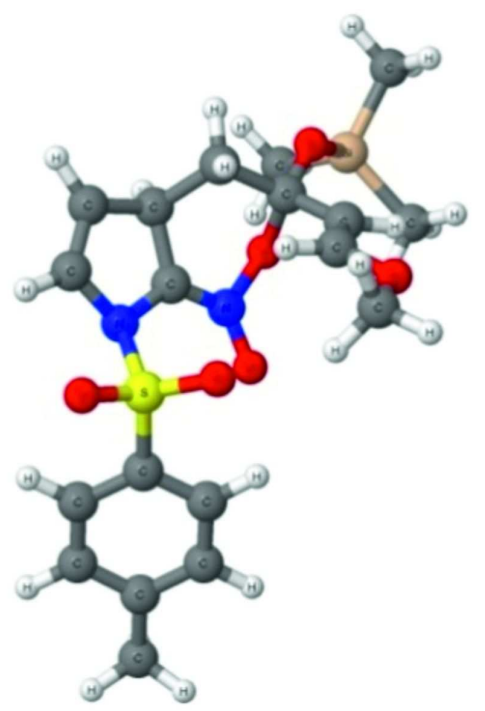

INT1

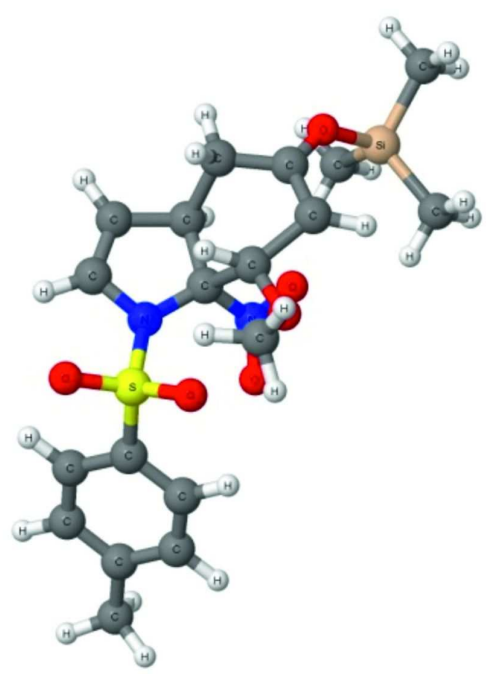

P1

Figure 1 Calculated [B3LYP/6-31G(d)] structures of transition states (TS1A, TS1B), intermediate Int1, and product $\mathbf{P 1}$ for channel 1. 
While in our previous studies on the reactions of nitro-substituted furans and thiophenes with a variety of dienes, ${ }^{3-5}$ only concerted albeit quite asynchronous reaction mechanisms (aka twostage one-step mechanisms ${ }^{24}$ ) could be found, in the present case of the reaction between 2-nitro1-tosylpyrrole 2c with Danishefsky's diene 5 both one-step (channels 2 and 4, Scheme 3) as well as two-step processes (channels 1 and 3, Scheme 3) could be found. The latter ones correspond to a hetero Diels-Alder reaction involving the endocyclic double and one $\mathrm{N}=\mathrm{O}$ bond of the nitro group of $\mathbf{2 c}$ as diene and the $\mathrm{C} 3=\mathrm{C} 4$ double bond of $\mathbf{5}$ as dienophile, followed by a $[3,3]$ sigmatropic rearrangement to the "normal" Diels-Alder cycloadduct (Scheme 4). Such participation of the nitro group in hetero Diels-Alder reactions leading to nitronates has been observed experimentally in reactions of nitroalkenes or 4,6-dinitrobenzofuroxanes. ${ }^{25,26}$ Moreover, the tandem hetero Diels-Alder/[3,3] sigmatropic shift mechanism has also been considered in calculations on the reaction of 3-nitro-1-tosylpyrrole with various dienes. ${ }^{27}$<smiles>C=C(/C=C/OC)O[Ga]</smiles>

2c
5<smiles>COC=CC1(OC)CC2C=CN([13CH3])C2=[N+]([O-])O1</smiles>

Int1<smiles>COC1=C[C@H](OC)[C@]2([N+](=O)[O-])[C@H](C=CN2[18OH])C1</smiles>

P1

Scheme 4 Reaction of $\mathbf{2 c}$ with $\mathbf{5}$ to the hetero Diels-Alder cycloadduct Int1 and rearrangement to the "normal" Diels-Alder cycloadduct P1. 
Formation of the hetero Diels-Alder cycloadduct Int3 involves a significantly higher barrier $(\sim 6$ $\mathrm{kcal} \mathrm{mol}^{-1}$ ) than formation of Int1. Therefore, this reaction path will not be considered in more detail. Both barriers for formation as well as rearrangement of Int1 are nearly equal and, hence, the [3,3] sigmatropic shift to $\mathbf{P 1}$ easily should occur. The barrier for the one-step process according to channel 2 is essentially equal to both barriers of the two-step endo/syn mechanism (channel 1). However, irrespective of the mechanism (concerted or two-step) formation of the Diels-Alder adducts is endergonic. The driving force for the reaction is the strongly exothermic elimination of nitrous acid to yield intermediate P5 (Scheme 5).<smiles>COC1=C[C@H](OC)Cc2ccn([As])c2[C@H](OC)C1</smiles>

Scheme 5 Extrusion of nitrous acid to product P5, followed by elimination/tautomerization to 5hydroxy-1-tosylindole Pf.

The barrier for elimination is significantly lower $\left(\sim 10 \mathrm{kcal} \mathrm{mol}^{-1}\right)$ than the barrier for formation of the Diels-Alder cycloadducts and hence formation of P5 should occur easily. Similarly, the irreversible extrusion of nitrous acid has been found to be responsible for the feasibility of the reaction of 1-nitronaphthalene with $5{ }^{28}$ Ultimately, according to the experimental findings P5 
reacts in analogy to nitrofurans and -thiophenes via extrusion of the trimethylsilyl group and methanol to yield the final product 5-hydroxy-1-tosylindole $\mathbf{P f}{ }^{1}$

\section{Conclusion}

Density functional calculations [B3LYP/6-31G(d)] with inclusion of solvent effects (benzene, CPCM model), dispersion and basis set superposition error corrections (gCP-D3) have been used to address the feasibility and mechanistic details of the Diels-Alder reaction between 2-nitro-1tosylpyrrole 2c and Danischefsky's diene 5. Both asynchronous concerted, i.e. two-stage one-step as well as stepwise mechanisms have been found. The stepwise mechanism consists in an initial hetero Diels-Alder reaction with the endocyclic double bond and one of the $\mathrm{N}=\mathrm{O}$ bonds acting as heterodiene and the $\mathrm{C} 3=\mathrm{C} 4$ bond of $\mathbf{5}$ as dienophile. This primary hetero Diels-Alder adduct easily undergoes a [3,3] sigmatropic rearrangement to the "normal" Diels-Alder adduct. Like in the analogous reaction of nitronaphthalenes, -furans, and -thiophenes, the large electrophilic character of $\mathbf{2 c}$ as indicated by DFT based reactivity indices, is responsible for the participation of $\mathbf{2 c}$ in Diels-Alder reactions with electron-rich dienes. However, further transformations of the initial Diels-Alder adduct, namely extrusion of nitrous acid followed by elimination of methanol and the trimethylsilyl group, are the driving forces for this reaction to occur.

\section{References}

(1) Della Rosa, C.; Kneeteman, M.; Mancini, P. Tetrahedron Lett. 2007, 48, 1435-1438. 
(2) Wenkert, E.; Moeller, P. D. R.; Piettre, S. R. J. Am. Chem. Soc. 1988, 110, 7188-7194.

(3) Brasca, R.; Kneeteman, M. N.; Mancini, P. M. E.; Fabian, W. M. F. J. Mol. Struct. (Theochem) 2009, 911, 124-131.

(4) Brasca, R.; Kneeteman, M. N.; Mancini, P. M. E.; Fabian, W. M. F. J. Mol. Struct. 2012, 1010, 158-168.

(5) Brasca, R.; Kneeteman, M. N.; Mancini, P. M. E.; Fabian, W. M. F. Eur. J. Org. Chem. 2011, 2011, 721-729.

(6) Stephens, P. J.; Devlin, F. J.; Chabalowski, C. F.; Frisch, M. J. J. Phys. Chem. 1994, 98, 11623-11627.

(7) Becke, A. D. J. Chem. Phys. 1993, 98, 5648-5652.

(8) Binning, R. C., Jr.; Curtiss, L. A. J. Comput. Chem. 1990, 11, 1206-1216.

(9) Kruse, H.; Grimme, S. J. Chem. Phys. 2012, 136, 154101.

(10) Kruse, H.; Goerigk, L.; Grimme, S. J. Org. Chem. 2012, 77, 10824-10834.

(11) Grimme, S.; Antony, J.; Ehrlich, S.; Krieg, H. J. Chem. Phys. 2010, 132, 154104/1154104/19.

(12) Grimme, S.; Ehrlich, S.; Goerigk, L. J. Comput. Chem. 2011, 32, 1456-1465.

(13) Barone, V.; Cossi, M. J. Phys. Chem. A 1998, 102, 1995-2001.

(14) Geerlings, P.; Ayers, P. W.; Toro-Labbé, A.; Chattaraj, P. K.; De Proft, F. Acc. Chem. Res. 2012, 45, 683-695.

(15) Zielinski, F.; Tognetti, V.; Joubert, L. Chem. Phys. Lett. 2012, 527, 67-72.

(16) Ess, D. H.; Jones, G. O.; Houk, K. N. Adv. Synth. Catal. 2006, 348, 2337-2361.

(17) Chattaraj, P. K.; Giri, S.; Duley, S. Chem. Rev. 2011, 111, PR43-PR75.

(18) Geerlings, P.; De Proft, F.; Langenaeker, W. Chem. Rev. 2003, 103, 1793-1873.

(19) Domingo, L. R.; Picher, M. T.; Sáez, J. A. J. Org. Chem. 2009, 74, 2726-2735.

(20) Gaussian 09, Revision C.01, Frisch, M. J.; Trucks, G. W.; Schlegel, H. B.; Scuseria, G. E.; Robb, M. A.; Cheeseman, J. R.; Scalmani, G.; Barone, V.; Mennucci, B.; Petersson, G. A.; Nakatsuji, H.; Caricato, M.; Li, X.; Hratchian, H. P.; Izmaylov, A. F.; Bloino, J.; Zheng, G.; Sonnenberg, J. L.; Hada, M.; Ehara, M.; Toyota, K.; Fukuda, R.; Hasegawa, J.; Ishida, M.; Nakajima, T.; Honda, Y.; Kitao, O.; Nakai, H.; Vreven, T.; Montgomery, J. A., Jr.; Peralta, J. E.; Ogliaro, F.; Bearpark, M.; Heyd, J. J.; Brothers, E.; Kudin, K. N.; Staroverov, V. N.; Kobayashi, R.; Normand, J.; Raghavachari, K.; Rendell, A.; Burant, J. C.; Iyengar, S. S.; 
Tomasi, J.; Cossi, M.; Rega, N.; Millam, N. J.; Klene, M.; Knox, J. E.; Cross, J. B.; Bakken, V.; Adamo, C.; Jaramillo, J.; Gomperts, R.; Stratmann, R. E.; Yazyev, O.; Austin, A. J.;

Cammi, R.; Pomelli, C.; Ochterski, J. W.; Martin, R. L.; Morokuma, K.; Zakrzewski, V. G.; Voth, G. A.; Salvador, P.; Dannenberg, J. J.; Dapprich, S.; Daniels, A. D.; Farkas, Ö.;

Foresman, J. B.; Ortiz, J. V.; Cioslowski, J.; Fox, D. J. Gaussian, Inc., Wallingford CT, 2009.

(21) O'Boyle, N.; Banck, M.; James, C.; Morley, C.; Vandermeersch, T.; Hutchison, G. J. Cheminform. 2011, 3, 33 .

(22) Jmol: an open-source Java viewer for chemical structures in 3D. http://www.jmol.org/

(23) Domingo, L. R.; Aurell, M. J.; Pérez, P.; Contreras, R. Tetrahedron 2002, 58, 4417-4423.

(24) Domingo, L. R.; Saez, J. A. Org. Biomol. Chem. 2009, 7, 3576-3583.

(25) Denmark, S. E.; Thorarensen, A. Chem. Rev. 1996, 96, 137-166.

(26) Sepulcri, P.; Halle, J. C.; Goumont, R.; Riou, D.; Terrier, F. J. Org. Chem. 1999, 64, 92549257.

(27) Gómez, M. V.; Aranda, A. I.; Moreno, A.; Cossío, F. P.; de Cózar, A.; Díaz-Ortiz, Á.; de la Hoz, A.; Prieto, P. Tetrahedron 2009, 65, 5328-5336.

(28) Domingo, L. R.; Jose Aurell, M.; Kneeteman, M. N.; Mancini, P. M. J. Mol. Struct. (Theochem) 2008, 853, 68-76. 